\title{
Medical planning for toxic releases into the community: the example of chlorine gas
}

\author{
P J BAXTER, ' P C DAVIES, ${ }^{2}$ * V MURRAY ${ }^{3}$ \\ From the University of Cambridge Clinical School, Department of Community Medicine,Cambridge CBI $2 E S^{1}$ \\ Health and Safety Executive, ${ }^{2}$ Hazardous Installations Policy Unit, London W2 4TF, and National Poisons \\ Unit, ${ }^{3}$ New Cross Hospital, London SE14 5ER, UK
}

\begin{abstract}
Emergency planning for a major accidental release of chlorine gas from industrial installations into the community is outlined for emergency services and hospitals. Realistic planning has been made possible with the advent of computer models for gas dispersion which may be used to estimate the numbers of deaths and casualties, according to their severity. For most purposes sufficient accuracy may be obtained by using a small number of computer analyses for the most serious reasonably foreseeable events under typical day and night weather conditions, and allowing for the emergency response to be scaled up or down according to the size of an actual release. In highly populated areas triage should be preplanned to deal with a large number of victims; field stations will be needed for the treatment and observation of minor casualties. The management and treatment of casualties is summarised. The best protection against a gas cloud is afforded by buildings whose windows, doors, and ventilation systems have been closed. Hospitals in the vicinity of an installation should draw up plans to protect patients and staff. Coordination in a disaster will require toxicological and epidemiological expertise and hospital plans should allow for this.
\end{abstract}

In Britain emergency planning for industrial disasters involving fires, explosions, or toxic releases has been given an impetus by the introduction of the Control of Major Accident Hazards (CIMAH) Regulations, 1984.' A key innovation of these regulations is the obligation placed on local authorities, at county level, to prepare emergency plans for communities around the so called top-tier sites; currently there are over 200 large inventory, top-tier sites involved. Hospital disaster plans are likely to require modification to deal with the potentially large number of casualties caused by a major chemical release into the community, and county emergency planners are legally obliged to consult health authorities when drawing up their offsite plans for these special installations. Chlorine is the commonest toxic gas for which planning has to be undertaken and the problems it presents to medical planners are typical of irritant gases in general-for instance, ammonia and sulphur dioxide. We provide

*This paper represents the view of the authors and should not be
regarded as a statement of HSE policy. Accepted 18 April 1988 instance, ammonia and sulphur dioxide. We provide here the background to the types of medical measures that need to be considered by emergency services and hospitals in planning for a toxic release.

\section{Toxic effects of chlorine and exposure thresholds}

The toxicology of chlorine has been reviewed elsewhere. $^{2-5}$ The most important consequences of exposure to the gas relate to its strong irritant action when in contact with the moist mucous membranes of the respiratory tract and, to a lesser extent, the eyes and skin. Death at high exposure is mainly from respiratory failure or cardiac arrest due to toxic pulmonary oedema. Bronchopneumonia may be a common and potentially lethal complication of pulmonary oedema from irritant gases.

Epidemiological and clinical data from accidents involving chlorine, and from its use in chemical warfare, are mostly inadequate for predicting the effects on man of chlorine exposure at different concentrations in the respired air. Dose response curves derived from experiments exposing animals to chlorine gas have been used to devise approximate toxic load curves for its effects on the human res- 
piratory tract. ${ }^{6}$ These curves are adjusted for human exposures, particularly to take into account the range of individual susceptibility of human populations comprising the young, the old, and the chronic sick who may be expected to react more adversely than others to exposure to chlorine. ${ }^{7}$

Using the adjusted curves, various thresholds have been suggested for the banding of medical effects at different concentrations of gas, and in 1986 the United Kingdom Chlorine Producers published a set of criteria representing the industry consensus from which emergency planners may select their banding thresholds according to the likely duration of an accidental gas release (table 1). ${ }^{8}$ In interpreting the table it should be noted that the toxic impact is not a simple reciprocal relation between the concentration of the gas in the inhaled air and the duration of exposure. Animal studies have shown that the relation is far from reciprocal and that for accidents involving exposures lasting between five and 20 minutes the concentration is more important than the duration in determining the effects on health. ${ }^{7}$

\section{Estimating the impact of a release of chlorine}

Realistic medical planning for a toxic release into the community is only possible if an estimate of the expected numbers of casualties can be undertaken. Fortunately, advances in knowledge on the probability of plant failure and the development of computer models for the dispersion of gas clouds now makes such planning feasible. This section summarises the method for predicting the numbers of fatal and non-fatal casualties.

Table 1 Hazard bands according to medical effects at three levels of exposure of the general population to chlorine gas ${ }^{8}$

\begin{tabular}{|c|c|c|}
\hline Hazard band & $\begin{array}{l}\text { Exposure } \\
\text { (conc ppm) }\end{array}$ & Effect \\
\hline $\begin{array}{l}\text { Distress } \\
3-15 \mathrm{ppm}\end{array}$ & $3-6$ & $\begin{array}{l}\text { Causes stinging or burning } \\
\text { sensation but tolerated } \\
\text { without undue ill effect for } \\
\text { up to } 1 \text { hour } \\
\text { Exposure for less than } \\
1 \text { minute causes coughing }\end{array}$ \\
\hline $\begin{array}{l}\text { Danger } \\
15-150 \mathrm{ppm}\end{array}$ & $100-150$ & $\begin{array}{l}\text { Dangerous for } \frac{1}{2}-1 \text { hour } \\
\text { exposure. Immediate } \\
\text { irritation to eyes, nose, and } \\
\text { throat, with cough and } \\
\text { lachrymation } \\
5-10 \text { minute exposure fatal } \\
\text { for some vulnerable victims }\end{array}$ \\
\hline $\begin{array}{l}\text { Fatal } \\
>150 \mathrm{ppm}\end{array}$ & $300-400$ & $\begin{array}{l}\text { A predicted average lethal } \\
\text { concentration for } 50 \% \text { of } \\
\text { active healthy people for } 30 \\
\text { minutes exposure } \\
\text { Fatal after brief exposure } \\
\text { (few breaths) }\end{array}$ \\
\hline
\end{tabular}

LIKELIHOOD OF ACCIDENTAL RELEASES

About 200 major accidents involving the accidental release of chlorine have been recorded worldwide since commercial production began just before the first world war (Health \& Safety Executive, unpublished). These have included the rupture of storage tanks and the failure of valves, process vessels, cylinders, containers, and drums but most incidents have occurred during the transportation of chlorine by rail, road, barge, or pipeline. It is noteworthy that most incidents have involved fairly small, if any, loss of life, and to date the most serious incident has been the rupture of a storage vessel in Romania in 1939 when 68 people died and 332 were reported injured (Health \& Safety Executive, unpublished).

Two main types of accidental release of chlorine may be identified: the sudden almost instantaneous release as a result of the failure of a storage tank or a continuous prolonged release from a crack or small hole in a piece of plant under pressure. Estimates can be made of the likelihood of the occurrence of the different types of plant failure that may be envisaged under normal commercial operations. The sudden failure of a storage tank is rare and may occur with a likelihood of about one in a million a year; certain types of failure in pipes, gaskets, and coupling hoses, on the other hand, may be 100-200 times more likely. A fundamental question for those engaged in major accident emergency planning is whether it is the largest possible, but usually rare, event which they should plan for or the more modest, but much more likely, release. The Health \& Safety Executive's view is that the detailed plan should be based on the most serious reasonably forseeable event, yet be sufficiently flexible to allow for the emergency response to be scaled up or down as necessary in relation to the actual size of the release that occurs. $^{10}$

Hence we suggest that the site operator needs to examine the plant and activities, and classify possible releases into three categories:

Category 1-Small but likely events such as leaks from flanges or corrosion holes in pipework-for instance, chlorine at the upper limit, releases of about $0.8 \mathrm{~kg} / \mathrm{s}(3 \mathrm{te} / \mathrm{h})$ lasting for between five and 30 minutes.

Category 2-Severe but reasonably forseeable events such as large holes in, or fractures of, a liquid chlorine pipe; or failure of a road tanker delivering coupling - for instance, release rates of between 3 and $8 \mathrm{~kg} / \mathrm{s}(10-30 \mathrm{te} / \mathrm{h})$ lasting for between five and 30 minutes.

Category 3-Large but unlikely events such as the catastrophic failure of a storage vessel-for instance, a quasi-instantaneous release of perhaps more than half the inventory of the storage vessel. 
CONSEQUENCES OF ACCIDENTAL RELEASES

When released to the atmosphere non-refrigerated liquefied chlorine boils instantaneously and flashes into vapour, extracting heat from itself and from its surroundings, including the air into which it is dispersed. With large releases from storage vessels that fail this results in a cold, dense, wide, low lying gas cloud that is then carried away by the wind, becoming larger and more dilute as it goes. With prolonged but relatively small releases from pipework, however, the results is a plume of gas, the length and breadth of which depends, among other factors, on the speed of the wind, the weather conditions, and the rate of release.

The area over which the gas cloud is likely to spread (and thus the concentration of gas in the air breathed at ground level) may be predicted approximately for different weather conditions by using computer models for these two types of release. With the models the site operator can estimate the size of the hazard zones around the plant for different sizes and types of release over a range of wind and weather conditions. For emergency planning purposes, however, it is not necessary to make extensive use of computer models. Sufficient accuracy may be obtained by interpolation and extrapolation from a few computer analyses. To aid manufacturers who do not have access to the necessary computer models the booklet published by the United Kingdom Chlorine Producers contains a simple set of charts and graphs that allow the user to determine the size and shape of hazard zones based on chlorine in air concentrations for a range of sizes of release in typical weather conditions. ${ }^{8}$ For example, the figure is taken from this booklet and shows various hazard zones for a range of release rates occurring in (a) typical, daytime conditions with a light wind and (b) adverse night time conditions with a temperature inversion and little air movement.

Using the technique outlined above, and described in detail in the booklet, ${ }^{8}$ the site operator can produce for the emergency planners sector diagrams (such as those in the figure) for each category of release showing the zones within which specified concentration levels are likely to be exceeded. With this information, we suggest that the planners may then prepare their detailed plan on the basis of the upper limit of the release rates and durations suggested in category 2 , but build into the plan sufficient flexibility to cater for the more likely category 1 releases.

Classification of releases in this way will also probably be of benefit in the early chaotic stages of an emergency because the message relayed from the site to the various emergency services can be short and explicit-for instance, "we have a category 1 release." As a result of preplanning and rehearsals this simple message automatically signifies to the recipients the nature and scale of the initial response that is required.
SCALE OF THE MEDICAL RESPONSE

Assesments of this type involve a large number of variables, including: the size of the release, its location in the works, its duration, whether people are indoors or outdoors, and the inherent variability in the sensitivity of individuals to chlorine. Accordingly, any attempt to predict the number likely to require medical treatment must in practice lead to estimates of ranges of likely casualties rather than precise numbers. Again, however, this fits in with the principle of basing detailed planning on a representative reasonably forseeable severe case but with inherent flexibility to deal with less or more serious events.

The following example illustrates the type of approach that might be adopted:

(1) As a result of a hazard analysis a site operator has informed the emergency planner that the worst reasonably foreseeable release would be of the order of $2.8 \mathrm{~kg} / \mathrm{s}(10 \mathrm{te} / \mathrm{h})$ for 20 minutes, and has provided sector diagrams for this release showing the variation in concentration with distance as per the figure.

(2) Using the toxicity data provided by the site operator and after consulting their medical advisers, the emergency planners decide to plan for responses at three exposure bands which may be plotted as zones on a map of the surrounding area:

(a) Those exposed to concentrations above $150 \mathrm{ppm}$ will be seriously ill, unable to help themselves, and will require prompt hospital attention. Some at the highest level of exposure or who are vulnerable may die; fatal zone.

(b) Those exposed to concentrations of 15-150 ppm will be feeling ill and will require attention and comforting. At the higher concentrations people will require admission to hospital; danger zone.

(c) Those exposed to concentrations of 3-15 ppm are likely to be distressed and will require information and assurance but, for most, urgent medical attention will not be necessary; distress zone.

A small percentage, however, of the exposed population is likely to be suffering from chronic asthma and cardiorespiratory disorders and they may respond much more severely than healthy people. Due allowance should be made for these and for the proportion of otherwise healthy people who have reactive airways and may suffer considerable discomfort from bronchospasm provoked by exposure at low concentrations.

(3) The site is in an urban area with some open spaces such as parks and gardens in the vicinity, but by using maps and census data it is estimated that the average population density is about 2000 people $/ \mathbf{k m}^{2}$. The calculation of the numbers of people likely to be affected in the above zones is therefore a relatively straightforward matter. In making estimates, however, the emergency planner has to take the following matters into account: 


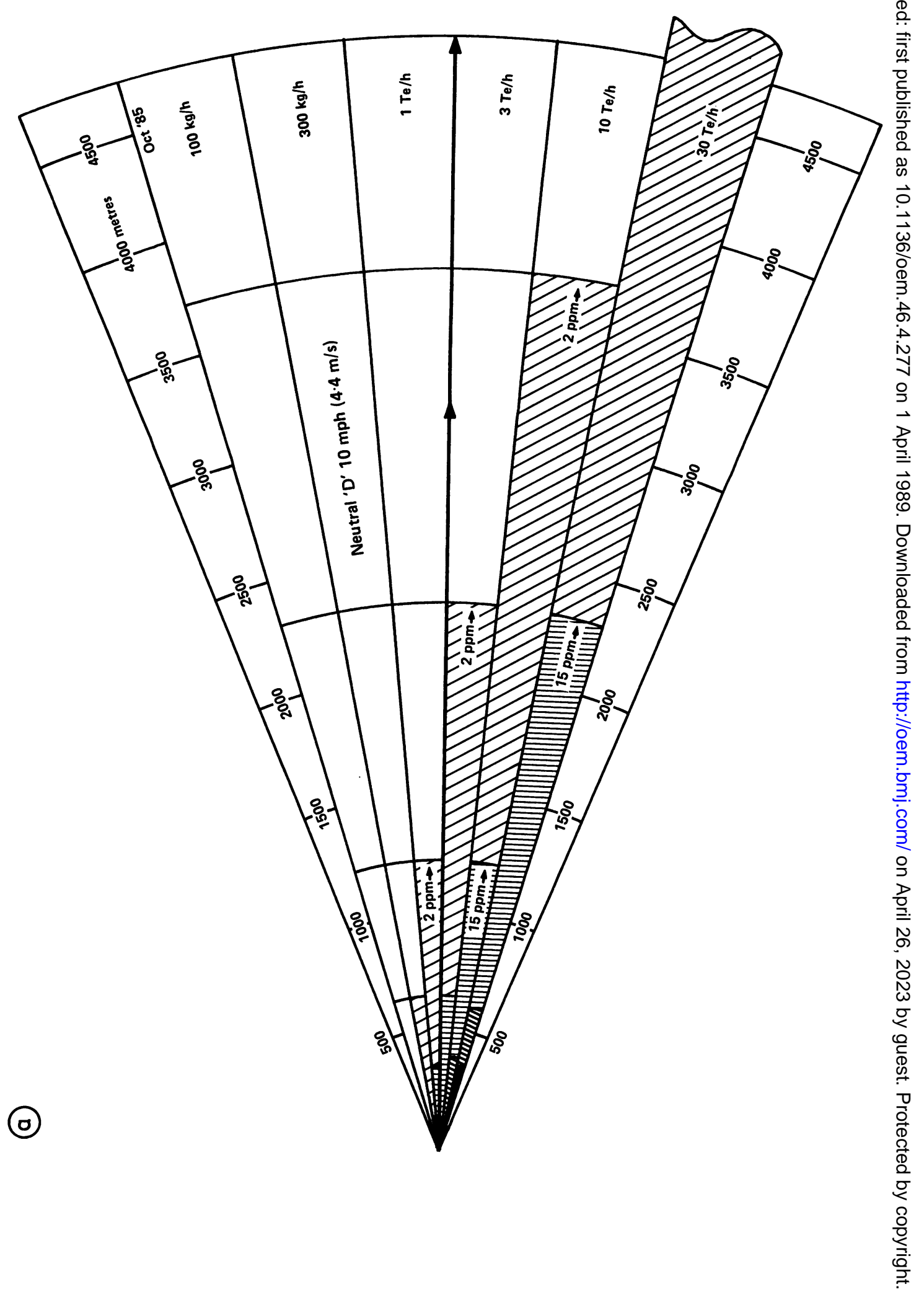




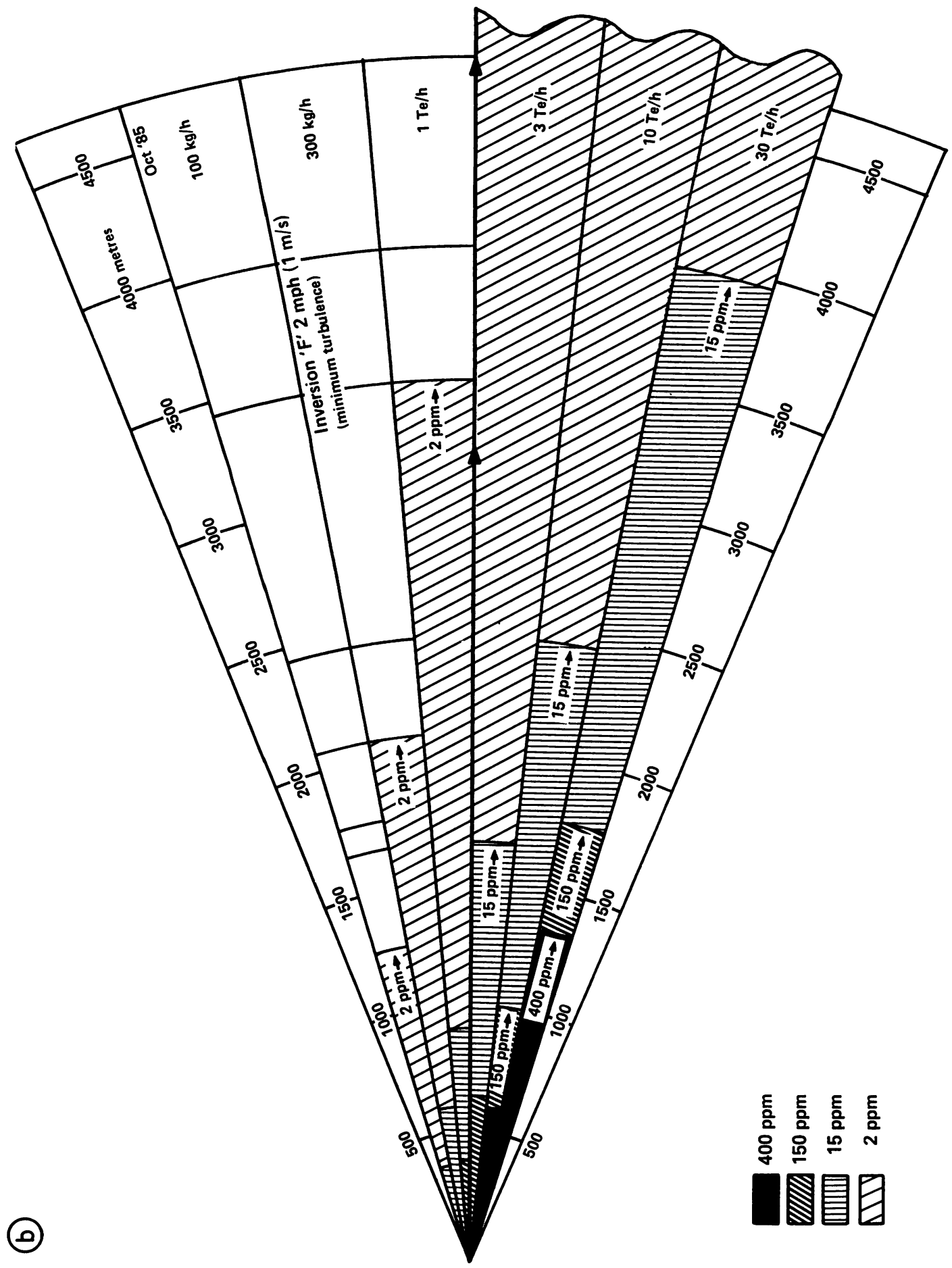


(a) The zone boundaries in diagrams such as the figure represent the outdoor concentrations. People inside buildings are afforded considerable protection from a toxic gas cloud because the gas has to penetrate into the building before it can begin to affect them." As a rule of thumb for domestic premises, if people come outside as soon as the cloud had passed the concentration they will have been exposed to indoors will be about half that which existed outdoors. Therefore for that part of the population who are indoors the fatal, danger, and distress zones would occur at about twice the concentration levels given above. Typically it may be assumed that in the daytime $80 \%$ of the population will be indoors (or can quickly escape indoors) and at night time this figure is virtually $100 \%$.

(b) People nearer the site will suffer more than those further away even if they are in the same zone.

(4) Bearing these factors in mind, the emergency planner can attempt to establish the ranges of the various types of casualty that the plan must deal with. The process is summarised for this example in table 2 where it may be seen that depending on the time of day of the release and the weather conditions the emergency services can expect to have to cope with between 60 to 400 people in the fatal zone, between 600 to 2300 in the danger zone, and between 5000 to 25000 in the distress zone. Although these casualty ranges are quite wide they can nevertheless provide a framework within which the emergency services, and especially the police and medical services, can make strategic and logistical plans. Furthermore, the uncertainty in the casualty estimates again emphasises the need for these plans to be flexible.

One other aspect that planners need to bear in mind when formulating their plans is that within each harmful effect zone there will be premises containing people who are especially sensitive to the effects of toxic irritant gases. Typically these will be establishments dealing with the old, the very young, and those with chronic respiratory disorders who may respond adversely to concentrations in the 3-15 ppm hazard band as noted above. Plume modelling for the $3 \mathrm{ppm} \frac{3}{\mathrm{~d}}$ level should therefore be used to determine which of $\stackrel{\mathbb{2}}{?}$ these establishments should be included in the emer- $\vec{\Rightarrow}$ gency plan. Special attention should be given to $\stackrel{\oplus}{+}$ hospitals where a high number of casualties may arise if windows, doors, and ventilation systems are not closed in time and if patients cannot be brought out into fresh air once the cloud has passed.

\section{Planning for medical casualties}

The number of casualties estimated above is $\operatorname{far} \overrightarrow{\vec{\omega}}$ greater than could be treated at a single hospital. This $\Omega$ fact, together with the possibility that the local major $\mathbb{\Phi}$ hospital may itself be in the path of the plume and? therefore unable to operate, means that emergency के plans will need to incorporate hospitals over a wide area. On the other hand, some chlorine installations, $\underset{Y}{V}$ particularly those used for water treatment, are sited in semirural or low population density areas where there will be no need to plan for anything like the large $\vec{\rightarrow}$ numbers cited in the above example. In this exampleo the numbers of people in the fatal and danger zones at the time of the release would be large enough for $\vec{\oplus}$ numerous deaths of rapid onset to occur, and for perhaps several hundred casualties requiring urgent $\square$ hospital treatment. Thousands will have suffered minor to moderately severe effects who, though not requiring urgent treatment, will wish to go or be taken to the nearest hospital for attention and advice. $\frac{\mathbb{\Phi}}{\mathbb{2}}$ Planning is essential if these non-urgent casualties are not to overload the hospitals and the roads leading to $\frac{\hat{O}}{3}$ them, thereby hindering treatment being provided to $\frac{3}{5}$ the most in need. The urgent and less urgent casualties must therefore be rapidly distinguished in an emergency by the process of triage which will also need to $\mathbb{\Phi}$ be preplanned.

TRIAGE

Triage is widely used for the practice of sorting $\delta$ casualties in battle or disasters according to priority for treatment. Confusion may arise on how triage $\frac{}{5}$

Table 2 Calculation of the number of casualties to be expected in a release of $2.8 \mathrm{~kg} / \mathrm{s}$ of chlorine for 20 minutes in an urban setting (population density $2000 / \mathrm{km}^{2}$ )

\begin{tabular}{|c|c|c|c|c|c|c|c|}
\hline & \multicolumn{3}{|c|}{ Hazard zone for people located outdoors } & \multicolumn{4}{|c|}{ Hazard zone for people located indoors } \\
\hline & Fatal & Danger & Distress & Fatal & Danger & Distress & \\
\hline $\begin{array}{l}\text { (1) Hazard range }(\mathrm{m}) \text { in } \mathrm{D}_{4.4} \text { conditions } \\
\text { (2) Hazard area }\left(\mathrm{km}^{2}\right)(\text { sector angle }=40) \\
\text { (3) No of people affected }=(2000 \times(2) \times \% \text { present })\end{array}$ & $\begin{array}{l}400 \\
0.056 \\
22\end{array}$ & $\begin{array}{l}1200 \\
0 \cdot 51 \\
204\end{array}$ & $\begin{array}{c}3700 \\
4 \cdot 8 \\
1920\end{array}$ & $\begin{array}{l}\text { release } \\
250 \\
0.022 \\
35\end{array}$ & $\begin{array}{l}850 \\
0 \cdot 25 \\
400\end{array}$ & $\begin{array}{l}2500 \\
2 \cdot 2 \\
3520\end{array}$ & \\
\hline $\begin{array}{l}\text { (4) Hazard area }\left(\mathrm{km}^{2}\right) \text { in } F_{2} \text { conditions } \\
\text { (5) Hazard area }\left(\mathrm{km}^{2}\right) \\
\text { (6) No of people affected }=(2000 \times(5))\end{array}$ & All indo & & & $\begin{array}{l}\text { e release } \\
750 \\
0 \cdot 2 \\
400\end{array}$ & $\begin{array}{l}1800 \\
2260\end{array}$ & $\begin{array}{c}6000 \\
12 \cdot 5 \\
25,000\end{array}$ & \\
\hline
\end{tabular}

NB For daytime releases the total number of people affected in each hazard zone will be the sum of those outdoors and indoors at the time; it is assumed that $80 \%$ will be indoors during the day compared with $100 \%$ at night (see text). 
should be conducted. In Britain most disasters involve relatively small numbers of casualties (usually fewer than 100) and the country is well covered by hospitals with modern facilities ${ }^{12}$; in addition, ambulance service personnel are well trained and can rapidly move casualties to hospitals while performing emergency resuscitation on the way. Triage should be undertaken in the receiving hospital and not in the field on the basis that all survivors, including the moribund, can expect to be treated. The triage officer does not undertake treatment himself but ensures that the casualties are assigned to the most appropriate hospital facilities.

On the other hand, in the event of thousands of victims (a result more commonly produced by natural rather than manmade disasters - but one which is not unknown with chemical major accidents-for instance, Bhopal) the goal of rapid and effective treatment for all may be unattainable and the emergency planning has to be more akin to that for battle casualties. Where there are overwhelming numbers of injured, or inadequate treatment facilities, the severely ill who are obviously beyond the scope of medical care will need to be separated from those urgent cases which could benefit from treatment in the field or in the limited hospital facilities available. Under these circumstances, triage is recommended to be undertaken in field stations where trained assistants to the triage officer can take over the task of resuscitation, maintaining airways and stabilising the seriously ill before they are transported to hospital. ${ }^{13} \mathrm{~A}$ second triage at the hospital, as described previously, is performed so that more definitive care may be speedily provided. Wherever triage is done, the general principle is the same: the sorting of casualties on the basis of the benefit they can expect from medical care and not only according to the severity of the trauma. ${ }^{13}$ As mentioned previously, the ultimate harm depends primarily on the concentration of chlorine gas and to a lesser extent on the period of exposure. Nevertheless, the initial trauma may be similar for those exposed to substantially different concentrations of gas. Therefore information about the original location of the victim - that is, some indication of the concentration and period of exposure-may be a useful factor to be taken into account at triage.

These general principles of casualty management have been discussed to show that the details of emergency planning for victims of chlorine gas will depend on the availability and scope of local medical facilities as well as the size of the disaster envisaged. Although chlorine has had worldwide industrial usage for the past 60 years, it is important to remember that major incidents are rare, and where lives have been lost the number of deaths has been few. The Romanian incident mentioned above had the highest number ever, with 68 deaths and 332 casualties. Thus planning for chlorine releases in Britain, and indeed in many other countries, should be in the first instance along the lines for small scale disasters in general, as has been described for British hospitals by Savage, ${ }^{12}$ but with the ability to scale up to the larger number of casualties if predicted by the type of calculations shown in our example.

There is another aspect in which the usual hospital disaster plans should be modified, in that they anticipate mainly trauma patients and nominate surgeons as the prime emergency staff. In chlorine or other gas releases physicians will be in the greatest demand and surgery may have little or no place unless the release was caused by an explosion resulting in blast or thermal injuries. For further details on emergency management and triage the reader should consult the references cited. ${ }^{1213}$

\section{SEARCH AND RESCUE}

In the first search and rescue phase most patients with lung irritation severe enough to cause pronounced bronchospasm or rapid onset pulmonary oedema would be distinguished by outward signs of respiratory distress, the most important being breathlessness at rest or on mild exertion. Auscultation of the chest would show wheeze or crackles or both. These patients require urgent treatment. The remainder with minor or moderate symptoms may be seen initially at field facilities such as predesignated schools or other public buildings staffed by medical and nursing staff who could administer symptomatic treatment. Clinical status should be monitored using indices such as blood pressure, pulse, respiratory rate, and peak flow rate. Most of these casualties will require no further attention, but a few could develop lung complications at a later stage, even after several hours have elapsed, when they will need to be sent to hospital.

The staff requirements for these non-urgent medical care facilities should not be hospital staff who might be needed in the hospitals to treat severe cases. The field role could be filled by general practitioners or hospital staff from those specialties not in urgent demand during the emergency period.

If it is evident that people have been seriously affected by an extensive chlorine release then a house to house search must be made by rescue services for people who have been overcome and who are too ill to leave the buildings. Patients with pre-existing respiratory complaints and the elderly are likely to be in this group. Rescuers may need to wear respiratory protection against pockets of gas built up inside the buildings, especially in basements and other poorly ventilated rooms. Neighbours and district nurses need to be concerned in reporting on the elderly or chronic sick they know of. 


\section{Treatment of casualties}

This section deals with the specific treatment for chlorine poisoning. General emergency measures such as first aid, resuscitation, and transport of casualties are not described.

\section{IN THE FIELD}

Casualties with minor exposures who have been referred to or who arrive at field stations will require reassurance and some-for instance, those with preexisting respiratory disorders such as asthma or chronic bronchitis-may need to be detained for observation. Most patients will settle quickly with rest. Symptomatic treatment for cough and soreness of the eyes and throat may need to be given. Supplementary oxygen should be available if needed and a bronchodilator drug given by metred aerosol or by injection in cases of mild bronchospasm. Eye irritation should be treated with an eyewash of water or sterile saline.

\section{IN THE HOSPITAL}

The hospital treatment of casualties is summarised in table 3. The degree of severity of pulmonary oedema in breathless patients will need to be established by measuring blood gases where possible and bronchodilators given to relieve bronchospasm. The possibility of laryngeal oedema causing respiratory obstruction should not be forgotten. The treatment of pulmonary oedema caused by irritant gases has not been well studied; in particular, the value of diuretics has not been determined and these should be used cautiously if at all. Patients who fail to respond to treatment may require mechanical ventilation. In the recovery phase chest infections should be treated vigorously with antibiotics.

Experience in the treatment of mass casualties from chlorine poisoning was gained in the early days of gas warfare during the first world war. In one gas attack 120 men - all of whom had severe shortness of breath and seemed in imminent danger of death-were admitted to a casualty clearing station at least six hours after exposure. Twenty nine died within 36 hours of admission and four died from chest infections two to four days after; the remainder recovered. ${ }^{14}$ Today most of these deaths could be prevented by the use of mechanical ventilators in hospitals. Thus at least a quarter of severe casualties may require mechanical ventilation, and clearly in a major disaster a national response would be required to mobilise enough ventilators.

\section{FOLLOW UP}

Survival from chlorine poisoning is usually stated to be followed by complete resolution of the pulmonary defects. ${ }^{15}$ Nevertheless, all survivors of gassing should
Table 3 Chlorine hospital management

A Immediate decontamination on arrival at hospital

Remove all contaminated clothing and thoroughly wash skin and eyes as necessary

B Assessment of patient

Examine mucous membrane, eyes, and skin for signs of corrosive injury

Check lung sounds, peak flow, and vital signs: if patient is known to have been heavily exposed or has a cough or difficulty in breathing at rest perform baseline chest $x$ ray examination Take brief medical history, with particular attention to any history of respiratory or cardiovascular disease

C Initial treatment

Oxygen: All patients identified as being at risk (see B above) should initially receive $100 \%$ oxygen, humidified if possible (unless this is contraindicated by their medical history). Oxygen concentration may subsequently be adjusted to the comfort of the patient

Bronchodilators: Salbutamol or terbutaline, used by nebuliser, may help relieve respiratory difficulties

Dose: Salbutamol-adults 2.5-5 mg increasing to $10 \mathrm{mg}$ if required children $2.5 \mathrm{mg}$ increasing to $5 \mathrm{mg}$ if required

Terbutaline-adults $2-5 \mathrm{mg}$ increasing to $10 \mathrm{mg}$ if required children up to $200 \mu \mathrm{g} / \mathrm{kg}$

Corticosteroids have not been proved to produce improvement in chlorine poisoning but have caused pronounced improvement after smoke inhalation. If patient exposed less than 4 hours previously and at risk of pulmonary injury (as defined in B above) steroids should be given.

Dose: Methylprednisolone-adults $2 \mathrm{~g}$ iv stat (or equivalent) children $\mathbf{4 0 0} \mathbf{m g}$ iv stat (or equivalent)

Laryngeal oedema: give corticosteroids (dosage as above) if patient develops laryngeal oedema

Skin burns should be treated as thermal burns

Eye damage requires ophthalmic referral

D Monitoring

Monitor respiratory function and arterial blood gases regularly: pulmonary oedema may occur up to 24 hours after exposure Patients who are well 24 hours after exposure may be discharged

E Pulmonary oedema

If pulmonary oedema occurs give $60 \%$ humidified oxygen by face mask or mechanically

If $\mathrm{pO}_{2}$ still cannot be maintained above $50 \mathrm{~mm} \mathrm{Hg}$ intubate and give positive end expiratory pressure (PEEP) ventilation

Intravenous fluids should be given with great caution as fluid overload is extremely dangerous in such patients: if this occurs diuretics such as frusemide are indicated.

be monitored to determine if there is any residual loss of lung function since the possibility of long term lung 웅 deterioration cannot be excluded on current $D$ knowledge.

\section{Protective measures by the local population}

Under the CIMAH regulations, the occupier has to ensure that the population living and working in the vicinity of the plant is informed about the protective measures they should adopt in the event of a release of $\frac{}{\varnothing}$ chlorine gas. ${ }^{1}$ Leaflets will have been sent to every? household and workplace and these may have been backed up by public meetings. Warning of a gas release may be given by a factory siren with a distinctive note and this would alert people to take 
action, but in some cases events will happen so rapidly that the presence of the gas will be the first signal for people to take precautionary measures.

As mentioned earlier, the most important protective measure is to be inside, closing all doors and windows. It is also desirable to keep physical activity to the minimum. Because chlorine is two and a half times denser than air, the best location is in an inner room with the lowest ventilation rate, preferably upstairs. It is important that the emergency services tell people to emerge into the open air when the gas has dispersed, otherwise exposure to chlorine that has built up inside the buildings will continue unnecessarily. Further information may be broadcast by emergency services in news flashes by the media in a prearranged manner. Other measures are likely to be insignificant compared with the expedient of seeking shelter indoors and making the buildings as impermeable as possible. Minor measures, such as breathing through dampened cloths, could also be advised.

Similar action should be planned for hospitals, schools, and other major buildings. There will be insufficient time to move patients from ground floor wards, for example, so the closing of all doors, windows, and ventilatory systems should be an essential part of the hospital plan.

\section{General emergency response measures}

When there are many casualties a disaster coordinating centre will need to be set up in accordance with existing major disaster plans, but in addition to the physician normally designated there should be a physician with epidemiological and toxicological expertise to provide advice and coordinate a medical investigative team. It is essential that the means are made available to survey rapidly the numbers and types of hospital casualties and to organise necropsies. Surveys of those people in the affected zone who have not come to hospital may also need to be rapidly initiated in order to evaluate the health effects on these groups. The investigative team performing the epidemiological assessment would have the important role of advising on the health needs of the casualties in general, supplying advice on the toxicological effects, and liaising with industry bodies, data banks, and key agencies such as the Health \& Safety Executive and the National Poisons Unit. The skills needed for these investigative tasks are in short supply in Britain and in a disaster may have to be rapidly assembled from national lists of specialists.

It should not always be assumed that chlorine alone has been released, and it is important to confirm as soon as possible that other chemicals are not involved. A leak from a large chlorine storage facility may be obvious but an explosion or fire could lead to other chemicals being involved, including intermediate chemicals from a process or the products of combustion. The collection and analysis of gases from a chemical accident is seldom feasible under emergency conditions and the exact materials released may have to be surmised after the event. It may be necessary for experts to take samples from the chemical process inside the plant as soon as it is safe to go in. If there is a suspicion that other chemicals or substances such as asbestos have been released, the populated area may have to be tested for ground contamination.

The area affected by the gas cloud needs to be demarcated as accurately as possible so that the exposed population may be identified. After the event, clues such as the defoliation of vegetation or the presence of dead animal carcases may help to show where the gas went; retrospective computer modelling of the dispersion of the gas cloud may also be useful.

Epidemiological data on the casualties should be collated when the disaster is over so that a scientific assessment can be made. Information on the effectiveness of the disaster planning will be important for future emergencies. The need for long term epidemiological studies, particularly of susceptible groups, should also be considered. ${ }^{15}$

We thank Drs G Volans, T Carter, T W Higgenbottam, and Messrs G Purdy and H M Sherriff for their comments on an early draft of this paper and the Health \& Safety Executive Process Safety Group of the Major Hazards Assessment Unit for their advice.

\section{References}

1 Health and Safety Executive. A guide to the control of industrial major accident hazards regulations 1984. London: HMSO, 1985.

2 Withers RMJ, Lees FP. The assessment of major hazards: the lethal toxicity of chlorine. Part 1. Review of information on toxicity. Journal of Hazardous Materials 1985;12:231-82.

3 Withers RMJ, Lees FP. The assessment of major hazards: the lethal toxicity of chlorine. Part 2. Model of toxicity to man. Journal of Hazardous Materials 1985;12:283-302.

4 Anonymous. Chlorine poisoning. Lancet 1984;i:321-2.

5 World Health Organisation. Chlorine and hydrogen chloride. Geneva: WHO, 1982. (Environmental health criteria No 21.)

6 Dicken ANA. The quantitative assessment of chlorine emission hazards. In: Chlorine bicentennial symposium, 1974. San Francisco: Electrochemical Society, 1974;244-56.

7 Davies PC, Hymes I. Chlorine toxicity criteria for hazard assessment. The Chemical Engineer 1985;415:30-3.

8 UK Chlorine Producers. General guidance on emergency planning within the CIMAH regulations for chlorine installations. Runcorn: ICI plc, 1986.

9 Pape RP, Nussey C. A basic approach for the analysis of risks from major toxic hazards. In: The assessment and control of major hazard. Rugby: Institute of Chemical Engineers, 1985:367-88.

10 Health \& Safety Executive. The control of industrial major accident hazards regulations 1984 (CIMAH); further guidance on emergency plans. London: HMSO, 1985.

11 Purdy G, Davies PC. Toxic gas incidents-some important considerations for emergency planning. In: The assessment and control of major hazard. Rugby: Institute of Chemical Engineers, 1985:257-68.

12 Savage PEA. Disasters. Hospital planning. Oxford: Pergamon Press, 1979.

13 Spirgi EH. Disaster management. Bern: Hans Huber Publishers, 1979.

14 Black JE, Glenny ET, McNee JW. Observation on 685 cases of poisoning by noxious gases used by the enemy. $\mathrm{Br} \mathrm{Med} \mathrm{J}$ 1915;ii:165-7.

15 Jones RN, Hughes JM, Glindmeyer $\mathbf{H}$, Weill $\mathbf{H}$. Lung function after acute chlorine exposure. Am Rev Respir Dis 1986;134:1190-5. 